\title{
Gobiernos Locales y Participación Política en America Latina: Procesos de Descentralización y Cambios electorales ${ }^{1}$
}

\author{
Por Detlef Nolte
}

El tema "gobiemor 'ocales y participación política" ha despertado últimamente un interés científico y periodístico creciente, principalmente por dos razones: (1) los procesos de descentralización llevados a cabo en los últimos años en América Latina 2 tuvieron como consecuencia una cierta revaloración de la política a nivel local3; y (2) hubo algunos resultados sumamente sorprendentes de elecciones municipales en varios países del continente. ¿Qué conexión existe entre ambos procesos? ¿Cómo se relacionan lo local y lo nacional en las elecciones municipales? ¿Qué perspectivas se abren respecto a una ampliación y profundización de la democracia en América Latina?

Hay que subrayar que en muchos países del continente se nutren esperanzas de que la profundización de la democracia local abra un camino para una renovación de la democracia a nivel nacional. Este enfoque está ligado a una vie ja tradición en el pensamiento político que percibe en la democracia en los municipios el germen de cualquier sistema democrático.

A continuación voy a proponer algunas piedras angulares de un mosaico político donde todavía queda mucho espacio por llenar antes de obtener un cuadro completo.

1 Este trabajo fue elaborado para el Simposio "Respuestas sociales a la política de descentralización", en el marco del 47॰ Congreso Intemacional de Americanistas, New Orleans 7.-11.7.1991.

2 Para un análisis comparativo de los procesos de descentralización en América Latina (y Europa) véase Dieter Nohlen (ed.), Descentralización Política y Consolidación Democrática. EuropaAmérica del Sur, Caracas 1991.

3 Véase p.ej. Paul Allies et al., Elección popular de alcaldes. Colombia y la experiencia internacional, Bogotá 1988; Federico Bervejillo, Gobiemo local en América Latina. Casos de Argentina, Chile, Brasil y Uruguay, en: Nohlen, Descentralización, págs. 279-299; Fernando Carrión et al., Municipio y democracia. Gobiemos locales en ciudades intermedias en América Latina, Santiago de Chile 1991; Gobiemos locales en América Latina, en: Medio Ambiente y Urbanización (Buenos Aires), vol. 7 (1989), no. 28; Gobiemos municipales y descentralización en América Latina, en: Revista Foro (Bogotá), no. 11 (1990), págs. 3-45; Enrique Groisman, ¿La hora de los municipios?, en: El Bimestre Político y Económico (Buenos Aires), enero/febrero 1990, págs. 3-8; Hilda Herzer I Pedro Pírez, Municipio y participación popular en América Latina, en: Desarrollo Económico (Buenos Aires), vol. 29, no. 114, págs. 187-205. 


\section{Tendencias}

\subsection{Descentralización político-administrativa y participación política: concepciones y problemas}

El tema de la descentralización está de moda en América Latina. Hay diferentes enfoques y objetivos relacionados con ese tema, que a veces son perseguidos paralelamente, causando así ciertas fricciones. 4 Conjuntamente con la ambigüedad del concepto, es probable que la superposición de estos objetivos diferentes, perseguidos por distintos actores políticos, expliquen la popularidad que encuentra el tema en la coyuntura actual.

Al lado de otros enfoques más bien tecnocráticos hay un enfoque que ve en la descentralización un instrumento para aumentar la participación política, para democratizar procesos políticos y sociales y para lograr una mayor proximidad entre las decisiones políticas y administrativas y los intereses de los ciudadanos en sus ámbitos comunitarios ("acercando la administración a los administrados"). 5 Descentralizando competencias políticas se pretende ampliar los espacios de participación por parte de la ciudadanía a nivel local (y regional), creando fosibilidades para colectividades sociales a nivel subnacional, de articular y realizar me jor sus intereses.

La descentralización de competencias políticas y el aumento de la participación política a nivel local son procesos que se pueden reforzar mutuamente: más competencias políticas a nivel local pueden crear un interés mayor en la política local, lo que a su vez estimula mayor participación política y la articulación de nuevos actores políticos. Ambos procesos pueden garantizar un mejor enlace entre la política local y los intereses de la ciudadanía (en el sentido de una mayor "eficiencia social"). 6 Este efecto puede a su vez causar nuevas presiones para una mayor ampliación de las competencias políticas de las autoridades locales.

Así, un incremento de las posibilidades de participación política en un proceso de descentralización político-administrativa, hace necesaria (a) la delegación de competencias políticas, desde el gobiemo central a entidades políticas a un nivel subnacional (municipios etc.), que son dotadas con suficientes fondos para el cumplimiento de sus nuevas tareas, y (b) la creación de mecanismos de participación para la ciudadanía a nivel municipal - por lo menos respecto a la elección de las autoridades locales (normalmente en forma directa). $\mathrm{O}$

4 Véase Detlef Nolte, Procesos de descentralización en América Latina: un enfoque comparativo, en: Nohlen, Descentralización, págs. 73-85.

5 Florencio Ceballos Bustos, Ideas preliminares sobre un sistema político democrático descentralizado territorialmente, en: Perfiles Liberales (Bogotá), no. 20 (1990).

6 Alejandro Rofman, Los municipios en el contexto de la descentralización, en: Hilda Herzer I Pedro Pírez (comp.), Gobiemo de la ciudad y crisis en la Argentina, Buenos Aires 1988, pág. 195. 
como escribe Bor ja ${ }^{7}$ "los elementos básicos que caracterizan a la descentralización entendida como proceso democratizador" son: "una estructura política deliberante y representativa (de elección directa preferentemente), dotada de autonomía en el ejercicio de sus competencias (lo cual supone poder tomar decisiones sin otros condicionamientos que los legales, es decir, tener una 'política' propia) y de carácter global (el ente descentralizado ideal no tiene una especialización funcional)."

Según los criterios presentados desde un enfoque participativo-democratizador se pueden esbozar tres áreas problemáticas en los procesos de descentralización político-administrativos:

(a) Existe una descentralización más formal que real en el sentido que no hay una delegación suficiente de competencias políticas, administrativas y económicas desde el gobiemo central (o estatal) a los gobiemos locales. En ese contexto la ampliación de los mecanismos participativos a nivel local podría formar parte de una estrategia para distraer de las deficiencias legitim -doras del gobiemo central, con el resultado de que la ciudadanía elige autoridades municipales con escasas competencias políticas. Esto puede traer como resultado la disminución del interés político a nivel local. La ciudadanía va a poner nuevamente un interés mayor en relacionarse con los órganos del poder central, disminuyendo al mismo tiempo la propensión hacia una mayor participación a nivel municipal.

(b) Hay una delegación de competencias (muchas veces en áreas como educación, salud, obras públicas etc.) pero sin la transferencia de los fondos necesarios para la prestación de esos servicios. Aquí entra el tema del reparto de los ingresos fiscales entre los diferentes niveles de gobierno y el derecho de los municipios para recaudar impuestos propios. En casi todos los países de América Latina hay quejas de las autoridades locales respecto de la falta de recursos adecuados para el cumplimiento de sus tareas 8 especialmente en los países donde se ejecuta una política de ajuste económico que trae como resultado recursos fiscales reducidos. Por eso, algunos observadores de los procesos de descentralización sostienen que el verdadero objetivo de la desconcentración de tareas estatales, consiste en desviar las críticas apuntadas al gobiemo central hacia los gobiemos locales (y regionales), por la mala calidad (o la falta) de servicios públicos, descentralizando y atomizando de esta manera la protesta social.

(c) También hay ura discusión de los procesos de descentralización político-administrativos que se refiere a la reducción del componente participativo a la elección de las autori-

7 Jordi Borja, Descentralización del Estado. Movimiento social y gestión local, Santiago de Chile 1987, pág. 51.

8 Véase p. ej. Federación Colombiana de Municipios, Memorias del primer período de gobiemos locales 1988-1990, Bogotá 1990. 
dades locales (cada cierto tiempo) y apunta a que en esas elecciones, por vía de la intervención de los partidos de arraigo nacional, se introduzca un fuerte elemento centralizador sumergiendo fuerzas locales. El debate actual en Chile sobre las leyes para la reforma municipal demuestra como en el proceso legislativo en el Congreso Nacional, los diferentes partidos políticos tratan, con visiones distintas, de estructurar los mecanismos de participación a nivel municipal de una manera que les asegure una optimización de su cuota de poder a nivel local.

A continuación profundizamos sobre el tema de los mecanismos de participación a nivel local, su arraigo, los resultados hasta ahora logrados, sus defectos y la búsqueda de su mejoramiento y ampliación.

\subsection{Descentralización y democratización: mecanismos y desideratas}

Visto desde una perspectiva institucional, se observa una tendencia casi general en América Latina de elegir al Poder Ejecutivo (los alcaldes) - y a las Asambleas Legislativas - a nivel local, por voto popular; antes eran muchas veces nombrados por el Ejecutivo Nacional o por órganos semirepresentativos. En cierto sentido, se puede hablar respecto de la segunda mitad de los años 80 y los principios de los 90 de un período de democratización de los municipios. Al mismo tiempo se crearon nuevas instancias con poder de decisión y elementos participativos a nivel regional, ampliándose de esa manera el espectro de instancias políticas con una legitimación directa.

Así, las nuevas constituciones provinciales promulgadas en Argentina desde 1986 han reforzado la autonomía y la autogestión municipal.9 En marzo de 1987, el gobiemo peruano promulgó una Ley de Bases de la Regionalización (ley 24650), dentro del mandato dado por la Constitución de 1979. Hasta fines de 1989, ya fueron creadas casi todas las regiones previstas por la nueva estructura político-administrativa del país, y ya empezaron a funcionar las Asambleas Regionales, como organismos representativos y legislativos de las mismas regiones. Hubo elecciones para cinco asambleas, paralelamente con las elecciones municipales, en diciembre de 1989, y para otras seis asambleas, paralelamente con las elecciones generales del 8 de abril de 1990. En marzo de 1988, en Colombia, fueron elegidos, por primera vez por voto popular, los alcaldes de más de mil municipios. En diciembre de 1989 fueron elegidos en Venezuela - también por primera vez - por voto popular, los alcaldes y los gobemadores. Además, se introdujeron cambios en el sistema de elección de los concejales para los concejos municipales, of reciendo al elector la altemativa de voto por lista o voto nominal. En el marco de su decisión de impulsar el plan de descentralización administrativa del estado, el presidente de Bolivia, Jaime Paz Zamora, puso a mediados de

Véase Pedro Frías et al., Las nuevas constituciones provinciales, Buenos Aires 1989. 
enero de 1990 a consideración del Poder Legislativo un proyecto de ley para la futura organización de los gobiernos departamentales. Esta ley tiene como objetivo reforzar los gobiemos departamentales y aumentar su legitimidad democrática. En Chile, en mayo de 1991 el gobiemo y el principal partido de oposición lograron un "acuerdo marco" para legislar con el fin de hacer posible la elección de los alcaldes y concejales en el primer semestre de 1992, democratizando de esta manera las estructuras administrativas desconcentradas que fueron creadas por el gobierno militar. Finalmente, el 26 de mayo de 1991 se llevaron a cabo por primera vez elecciones democráticas de los alcaldes en Paraguay.

¿Está entonces la democracia local en pleno auge? La respuesta depende de un análisis a fondo de los contextos políticos y sociales donde se llevaron a cabo las reformas políticas mencionadas. Una mayor autonomía local no es garantía de una mayor democracia local. El ambiente local es propicio para la institucionalización de relaciones clientelísticas entre el electorado y los poderes ejecutivo y legislativo del municipio. Existe la posibilidad de que las elecciones a nivel local no conduzcan a una mayor injerencia de los ciudadanos en la política, ni a una renovación de los cuadros políticos a nivel local, sino más bien a la ratificación de las estructuras del poder político-económicas en los municipios y el reforzamiento de su peso político en la política nacional, en el sentido de una "municipalización del poder político"10. En este contexto, hay que recordar que en el transcurso de la historia, no solamente en América Latina los procesos de centralización del poder político, a costo de los poderes locales, muchas veces tuvieron un auge democratizante. Por otro lado se debe relativizar el argumento histórico. Los procesos centralizadores tuvieron su momento histórico, cuando aportaron a la democratización política. Pero ahora como reacción a procesos de sobrecentralización existe un contramovimiento de descentralización, que tiene un potencial democratizante.

Desde un enfoque democratizador, uno de los objetivos centrales de la descentralización,consiste en e aumento de la participación política de la ciudadanía. En esta perspectiva resulta especialmente interesante analizar las experiencias de países donde recientemente fueron introducidos nuevos mecanismos electorales a nivel local para aumentar la legitimidad política y crear oportunidades para una mayor participación. Los resultados no son muy alentadores:

- En Colombia, en marzo de 1988, participaron en las primeras elecciones populares de los alcaldes solamente el $67 \%$ de los inscritos y el $43 \%$ de los electores potenciales 11 , un poco más que en el año 1986, cuando fueron elegidos solamente los miembros de los conce jos municipales. En las segundas elecciones municipales en Colombia, el $11 \mathrm{de}$

10 Pilar Gaitán, Primera elección popular de alcaldes: expectativas y frustraciones, en: Análisis Política (Bogotá), no. 4 (1988), pág. 78.

11 Gaitán, Primera elección, pág. 67. 
marzo 1990, la tasa de participación decreció aún más: votaron el $54 \%$ de los inscritos. 12

- En diciembre de 1989, en la primera elección directa de los gobernadores y alcaldes en Venezuela, participaron solamenteel $46 \%$ de los votantes, mientras que en las elecciones municipales anteriores había participado un $73 \%$ (1979) y un $59 \%$ (1984). Los electores tampoco apreciaron el cambio del sistema electoral para los concejos municipales, que abrió al ciudadano la opción entre un voto por lista o un voto nominal.13

Se debe analizar estos resultados, que permiten diferentes interpretaciones. Lo más probable es que en los resultados repercutan procesos políticos de nivel nacional. En ese sentido la alta abstención es, o un indicador de una baja legitimidad del sistema político, o una protesta temporal contra el manejo político por parte del gobiemo central. La alta tasa de no-votantes también puede implicar un rechazo a una política de descentralización más formal que real.

Analizando las repercusiones de los nuevos mecanismos democráticos a nivel local, no podemos esperar resultados uniformes. La tasa de participación de la ciudadanía depende del contexto político. Así en la elección para la alcaldía de Asunción (Paraguay) participaron el $82 \%$ de los inscriptos. Y con respecto a Chile se puede prever ya que la participación en las elecciones municipales previstas para junio de 1992 va a ser mucho más alta que en Venezuela y Colombia, pero seguramente no tan alta como en las elecciones generales de 1989 (95\%).

Como ya se ha mencionado, hay una discusión crítica sobre las deficiencias de los mecanismos de participación a nivel local, como p.ej. las limitaciones del mecanismo electoral y sobre tendencias centralizantes en los partidos políticos. Se cuestiona también la combinación de las elecciones a nivel local con elecciones a nivel nacional, porque en ese caso normalmente dominan éstas el escenario local.

El caso extremo se da cuando existe una subordinación formal de las elecciones locales, como p.ej. en Uruguay y durante mucho tiempo (1958-1973) en Venezuela: hay listas cerradas que impiden votar por diferentes partidos a nivel local y nacional.

12 Sabine Kurtenbach, Die Wahlen und neue Verfassung in Kolumbien, en: Lateinamerika. Analysen - Daten - Dokumentation (Hamburg), no. 18 ("Wahlen 1990/1991").

13 Véase José Virtur so, Elecciones de Alcaldes, en: SIC (Caracas), vol. 53, no. 522 (1990), págs. 8082; José Virtuoso, Elecciones de Concejales, en: SIC (Caracas), vol. 53, no. 523 (1990), págs. 116117; Friedrich Welsch / Nikolaus Werz, Venezuela. Wahlen und Politik zum Ausgang der 80er Jahre, Freiburg 1990. 
Es objeto de discusión ampliar los mecanismos de participación a nivel local (y regional) más allá de la elección de las autoridades y relativizar el peso de los partidos políticos, vistos en cierto sentido como agentes centralizadores. Forman parte de los mecanismos debatidos: la reversibildad del voto (revocatoria del mandato) para contrarrestar el riesgo de una autonomización de las autoridades elegidas; la injerencia directa en las decisiones políticas (referéndum, consulta popular, derecho de iniciativa etc.); y mecanismos corporativos donde organizaciones sociales (como p.ej. sindicatos, organizaciones de pobladores o también gremios patronales) tienen un derecho de participar en órganos representativos.

La reivindicación de una ampliación de los mecanismos de participación a nivel local ya encontró voz y resonancia en la política de varios países de América Latina. Así p.ej. muchas de las nuevas constituciones provinciales en Argentina incluyen a nivel municipal "la posibilidad del ejercicio de los institutos de democracia directa o semidirecta, como la iniciativa, el referéndum y la revocatoria".14 En su propuesta para la Asamblea Nacional Constituyente, la Federación Colombiana de Municipios 15 se queja de "que las instituciones constitucionales vigentes tienden a reducir la participación ciudadana al momento electoral" y que "la Constitución y la ley favorecen las estructuras partidistas". Al lado de un sistema electoral perfeccionado (incluídos mecanismos de revocatoria del mandato) la Federación propone instituciones "como la consulta popular, el referéndum, la posibilidad de formular observaciones a los actos de carácter general antes de su expedición y los sistemas de injerencia en la toma de decisiones sobre la ejecución presupuestal, la ejecución de obras y la evaluación de resultados."

Además, en aquellos países donde los municipios tienen una jurisdicción territorial (p.ej. los departamentos en Uruguay) o poblacional (p. ej. en las grandes ciudades) demasiado extensa se buscan mecanismos para una mayor descentralización a nivel local - creando nuevas comunas o rreando nuevos órganos participativos a nivel de barrios, como p.ej. los consejos vecinales en Buenos Aires, los Cabildos abiertos y las asambleas vecinales en algunos distritos de Lima, los centros comunales zonales en Montevideo y las juntas administrativas locales en varias ciudades de Colombia. En cierto sentido se trata de una descentralización intramunicipal.

En esos procesos de descentralización intramunicipal normalmente se presentan problemas en las siguientes áreas:

14 Frías et al., Constituciones provinciales, pág. 213.

15 Federación Colombiana de Municipios, El reordenamiento de la administración territorial. Propuesta nomnativa de la Federación Colombiana de Municipios para la Asamblea Nacional Constituyente, Bogotá 1991. 
- el grado de autonomía de los entes creados en relación con los órganos y estructuras centrales del gobierno local;

- el modo de participación de la ciudadanía y de las organizaciones sociales existentes a nivel subcomunal en la creación de los órganos decentralizados y el nombramiento de sus miembros;

- si su constitución es facultativa u optativa, dependiente de la voluntad de órganos del gobiemo local c’ntral;

- las competencias de esos órganos: si tienen facultades reales o si funcionan solamente como órgano de transmisión de las decisiones del gobiemo municipal a los ciudadanos en las diferentes zonas municipales;

- su integración en los procesos de decisión y planificación a nivel municipal.

Según los resultados que conocemos - me refiero especialmente al caso colombiano 16 , porque es el mejor documentado - las elecciones a nivel subcomunal no han inducido ni en un aumento de la participación de la ciudadanía, ni en cambios en las pautas de participación (fue confirmada p.ej. la importancia de mecanismos clientilísticos).

Por esa razón, las esperanzas de una renovación del sistema democrático a nivel local y sublocal están por ahora bastante reprimidas: Se presentaba una tendencia general - como era de esperar - de percibir los mecanismos de participación nuevos a nivel subcomunal, como instrumentos para realizar intereses inmediatos del ámbito barrial (servicios públicos, equipamiento colectivo etc.). Además se mostraron grandes diferencias según el estatus socioecónomico de los barrios: en la tasa de participación, en los modos de participación y en el alcance de los objetivos perseguidos. Existe la tendencia de que en los barrios altos y medio-altos hay una tasa de participación más alta, son perseguidos objetivos más globales y existe más indepr.ıdecia respecto de las burocracias municipales y partidarias. Pero esa tendencia general es mediatizada por factores de la coyuntura política y de la infraestructura político-social existente (partidos, organizaciones intermedias) en los barrios respectivos. En barrios marginales con fuertes organizaciones sociales existe más independencia respecto de los partidos y una tasa más alta de participación.

Respecto a los otros mecanismos mencionados en relación con una ampliación del potencial de participación a nivel local, se tiene que advertir que muchos de esos mecanismos

16 Véase Sonia Eljach, Las Juntas Administradoras Locales: ¿en qué va este proceso?, en: Revista Foro (Bogotá), no. 9 (1989), págs. 94-104; Esperanza González / Fernando Duque, La elección de Juntas Administradoras Locales en Cali, en: Revista Foro (Bogotá), no. 12 (1990), págs. 77-88; Vincent Goueset, Las elecciones municipales de marzo en Bogotá. Estudio de geografía electoral, en: Revista Foro (Bogotá), no. 9 (1988), págs. 68-73. 
quedan hasta ahora en un nivel declamatorio, sin pasos concretos para ponerles en la práctica. Así, p.ej. la consulta popular sobre asuntos municipales prevista en la legislación colombiana queda sin reglamentación. Los proyectos de ley publicados incluyeron muchas restricciones respecto a la convocatoria y el contenido de las consultas populares.

En relación con la inclusión de mecanismos de una representación corporativa es necesario hacer algunas advertencias: esos mecanismos pueden tener un enfoque incluyente o un enfoque excluyente. En el primer caso, el objetivo es dar más peso a sectores de la población normalmente postergados en el proceso político. En el segundo caso, se pretende privilegiar algunos intereses a costa de otros, diminuyendo al mismo tiempo la importancia de la elección democrática de representantes políticos por toda la ciudadanía. Además, siempre hay que preguntarse qué grado de representatividad tienen las organizaciones que participan en órganos representativos con carácter corporativo.

Un ejemplo para una instrumentalización netamente excluyente de los mecanismos de una representación corporativa son los Conse jos de Desarrollo Comunal (CODECO), creados durante el régimen militar en Chile, como substituto de un parlamento municipal elegido democráticamente. En los CODECOS, que tenían competencias reducidas, estaban representadas solamente organizaciones sociales afines al régimen. Un enfoque participativo tuvieron los cabildos abiertos y asambleas vecinales en algunos distritos de Lima en la primera mitad de los 80 , donde organizaciones populares encontraron una respresentación para participar en la toma de decisiones a nivel distrital.17 En los parlamentos regionales (asambleas regionales) creadas en el marco de la política de regionalización en Perú en los años 1989/90, alrededor de un tercio de los miembros son delegados de "instituciones representativas de las actividades económico-sociales y culturales".18

Sería sumamente interesante confrontar las experiencias de nuevos mecanismos de participación en los diferentes países de América Latina. Hasta ahora faltan estudios comparativos sobre ese tema.

La temática de la participación política a nivel local (sus diferentes formas y sus perspectivas) es amplia. En este trabajo se pueden tocar solamente algunos aspectos. Queda fuera, en

17 Véase Luis Chirinos, Participación vecinal en el municipio de Lima metropolitana, en: Socialismo y Participación (Lima), no. 36 (1986), págs. 1-27.

18 Véase Secretaría de Prensa de la Presidencia de República (Peru), Elecciones Regionales. 12 de noviembre - Cartilla Urbana, Lima 1989. 
gran parte, todo lo relacionado con los movimientos sociales ${ }^{19}$ y las organizaciones nogubemamentales: su papel en la democratización de los modos de su involucración en los procesos de formulación y ejecución de la política local (todo lo relacionado con el fortalecimiento del tejido social).

Sobre este tema existen varios estudios interesantes en los diferentes países del continente. Basta mencionar los movimientos y paros cívicos en Colombia. 20 Sin entrar más en el tema me gustaría hacer dos advertencias:

- Las experiencias parecen enseñar que a la larga los partidos partidos políticos casi siempre logran dominar el escenario político, absorbiendo a los movimientos sociales: o apoderándose de sus temas o marginándoles del proceso político.

- Los movimientrs sociales acusan un ciclo vital con auge y descenso. En cambio los partidos políticos manifestan una vida más duradera. Por eso hay que aclarar que en la discusión sobre nuevos mecanismos de participación a nivel local es necesario pensar más allá de fenómenos coyunturales, dando más importancia a estructuras políticas con una cierta continuidad.

A continuación me voy a referir nuevamente a los mecanismos de participación más tradicionales, como son las elecciones de las autoridades locales. También en esos procesos más convencionales se manifiestan tendencias renovadoras. Hay que recordar que para muchos ciudadanos, probablemente para la mayoría, las elecciones son el mecanismo más importante (o el único) para expresar sus preferencias políticas.

\subsection{Elecciones con sorpresas}

En algunos países de América Latina las elecciones municipales de los ultimos años presentaron resultados sumamente interesantes porque diferieron o en general o en ciudades importantes de la zonstelación política a nivel nacional. Exponiendo esos resultados sorprendentes se da al mismo tiempo una breve descripición del contexto institucional especialmente respecto al tema de la descentralización - donde se llevaron a cabo esos

19 Véase p. ej. Pedro Rodríguez Santana, Movimientos sociales, gobiemos locales y democracia, en: Revista Foro (Bogotá), no. 8 (1989),págs. 20-31.

20 Véase William C. Cartier, Civic Movements and Politics in Colombia, en: Canadian Journal of Latin American and Caribbean Studies, vol. 12 (1988), no. 24, págs. 103-120; Pedro Rodríguez Santana, Los movimientos civicos: el nuevo fenómeno electoral, en: Revista Foro (Bogotá), no. 6 (1988), págs. 47 -61. 
elecciones. Tratamos solamente algunos casos ilustrativos, que seguramente se podrían complementar con otros, como p. ej. los éxitos de CONDEPA y de la Unión Cívica Solidaridad (UCS) en las elecciones municipales en Bolivia - especialmente en La Paz - en diciembre de 1989 (y nuevamente en diciembre de 1991).21

Brasil: La nueva constitución brasileña, promulgada en octubre de 1988, contiene un fuerte elemento democratizador respecto de los municipios, no solamente en cuanto a la elección de las autoridades locales (prefecto, cámara de concejales/vereadores), sino también respecto a la inclusión de mecanismos participativos, como el plebiscito, el referéndum y la iniciativa popular. La última tiene que contar - según la constitución - con el apoyo de por lo menos $(5 \%)$ del electorado. Pero hay que anotar que los mecanismos incluídos en la constitución todavía están en proceso de implementación por vía de la elaboración de nuevas constituciones estatales (Brasil es un república federativa) y nuevas cartas orgánicas municipales.

En las elecciones municipales llevadas a cabo en Brasil el 15 de noviembre 1988 hubo un deslizamiento hacia la izquierda. El Partido de Trabalhadores (PT) ganó p.ej. en Sâo Paulo, la ciudad más grande de América del Sur. El resultado de las elecciones fue interpretado al principio esencialmente como voto de protesta y rechazo contra los partidos gobernantes. Visto con más distancia, se vislumbraba ya en ese momento la derrota de los partidos tradicionales en las elecciones presidenciales de 1989.

En Perú la discusión sobre la descentralización se ha concentrado en los últimos años más en el tema de la regionalización del país que en un reforzamiento del componente municipal. Sin embargo, la autonomía administrativa y económica de los municipios y sus elementos democráticos (los alcaldes y los miembros de los conse jos son elegidos directamente) fueron reforzados en la nueva constitución de 1979. En la actualidad todo el proceso de descentralización política está afectado por la crisis económica del país y por el problema de la violencia política (guerrilla, contrainsurgencia, narcotráfico).

Las elecciones municipales llevadas a cabo en el Perú el 12 de noviembre 1989 causaron una gran sorpresa22: en Lima ganó el empresario y locutor de televisión Ricardo Belmont, quien se presentó como candidato independiente. FREDEMO se estableció como segunda fuerza, el APRA y la izquierda sufrieron una grave derrota. Ya en ese momento era perceptible una tendencia ye se mostraba con más nitidez en las elecciones generales de abril de

21 Véase Jorge Lazarte, Elecciones 1989. La crisis entre lo que se va y lo que emerge, en: Presencia (La Paz), 5.12.1989.

22 Véase Marissa Bisso, Resultado de comicios municipales trastoca mapa político del Penú, en: Noticias Aliadas (Lima), 23.11.1989; Rafael Roncaglio, Elecciones en Lima: cifras testaduras, en: Que Hacer (Lima), no. 62 (1989), págs. 12-20. 
1990: el desgaste del APRA, la crisis de la izquierda, la volatibilidad de los electores y su inclinación de apoyar a candidatos independientes en vez de políticos profesionales.

Argentina: En el federalismo argentino el régimen municipal es reglamentado en las diferentes constituciones provinciales. Las reformas de esas constituciones, llevadas a cabo en los últimos años, resultaron generalmente en un aumento de la autonomía de los municipios. En la actualidad los municipios pasan, como el gobiemo central y los gobiemos provinciales, por una situación muy grave de ingresos fiscales restringidos y grandes problemas para cumplir con sus funciones.

A fines de noviembre de 1989 hubo elecciones para las intendencias municipales en las dos ciudades más importantes de la provincia de Santa Fe, Rosario y Santa Fe(ciudad). En ambas oportunidades fueron derrotados los candidatos de los dos parti dos dominantes de Argentina, los peronistas y el Partido Radical. Triunfaron candidatos de partidos menores: en Rosario ganó un socialista, en Santa Fe (capital) el candidato del Partido Demócrata Progresista. Los resultados fueron interpretados como un voto de rechazo contra el gobiemo y los partidos dominantes de la política argentina. 23 Estos son solamente dos ejemplos de elecciones en ciudades importantes de Argentina, donde se manifestó ese voto de castigo contra el gobierno y el principal partido de la oposición. Algo parecido sucedió en agosto de 1990, cuando en un plebiscito dos tercios de los votantes rechazaron la propuesta para una nueva constitución de la provincia de Buenos Aires, que había sido apoyada por los peronistas y los radicales.

Tomando como punto de referencia la victoria sorprendente de Fujimori en las elecciones presidenciales en Perú, se ha impuesto en Argentina, así como también en otros países de América Latina, el término de la "fujimorización" de la política para denominar a esos fenómenos de victorias electorales de "outsiders" y los masivos votos de rechazo a los partidos dominante. 24

En Uruguay no existe en la cultura política una tradición fuerte de "federalismo" y "municipalismo". Pero hay una discusión y una producción académica muy amplia sobre el tema de la descentralización. En la actualidad, después de las elecciones generales de noviembre de 1989, el debate sobre el reparto de las competencias y recursos entre los diferentes niveles de gobiemo tiene un punto de referencia más real. Mientras a nivel nacional ganaron el Partido Nacional y Luis A. Lacalle con 38,8 \%, en la capital Montevideo, donde

23 Véase Enrique Zuleta Puceiro, Las elecciones en Santa Fe, en: El Economista (Buenos Aires), 1.12.1989, pág. 4.

24 Véase Arturo D. Coyle, Una doble luz roja: el "no" de Buenos Aires y el sopresivo vuelo de Fujimori, en: Busqueda (Montevideo), 16.8.1990, pág. 32; "'Fujimorización'en Argentina", en: El País (Madrid), 18.8.1990, pág. 8; Daniel Gianelli, El "fenómeno Fujimori", en: Busqueda (Montevideo), 16.-22.5.1991, pág. 2 . 
vive alrededor de la mitad de la población, ganó con $34 \%$ el candidato del Frente Amplio, el socialista Tabaré Vázquez, quien, según las encuestas, disfruta de un respaldo político en la población de Montevideo mucho más alto que el presidente Lacalle - factum que le transforma en un serio contendiente para las proximas elecciones presidenciales. Además se comenzó con una mayor descentralización intramunicipal en Montevideo, creándose centros comunales zonales en los barrios.

Paraguay: Paraguay es una república unitaria. Sus 19 departamentos son administrados por representantes del gobiemo central. No hay un debate sobre una verdadera descentralización política-administrativa, pero sí sobre mayores competencias y mayor autonomía de los municipios, ya postuladas en la constitución vigente. 25

El 26 de mayo 1991 hubo por primera vez elecciones directas para las alcadías, que mostraron el avance del proceso democrático en ese país. El partido gobemante, el Partido Colorado, sufrió grandes pérdidas en comparación con las elecciones generales del $1^{\circ}$ de mayo de 1989. Sin embargo, mantuvo su posición de mayor fuerza política, ayudado por su respaldo en municipios pequeños con características rurales. Pero al mismo tiempo las elecciones a nivel local crearon espacios políticos para la articulación de nuevos actores políticos en los ámbitos más urbanos. Así, por ejemplo, el dirigente sindical, Carlos Alberto Filizzola, líder de ina agrupación llamada "Movimiento Independiente Asunción para Todos" ganó las elecciones para la alcadía de la capital con $34,3 \%$ de los votos emitidos, contra $27 \%$ del candidato colorado y $19,6 \%$ del candidato del principal partido de la oposición, el Partido Liberal. Muchos observadores interpretaron el resultado de las elecciones municipales como el comienzo de una reestructuración del sistema de partidos en Paraguay y de un nuevo reparto del poder político.

\section{Elecciones a nivel local: perspectivas de cambio político y de avances demócra- ticos a nivel local y nacional}

¿Cómo se relacionan lo local y lo nacional en las elecciones municipales? ¿Existe una conexión entre los fenómenos descritos en las elecciones municipales y los procesos de descentralización a nivel local? Desde una perspectiva muy formal, sí. La existencia de mecanismos de participación política a nivel local es una condición previa. Pero un análisis provisorio - faltan todavía estudios comparativos sobre elecciones municipales en América Latina - parece demostrar que factores locales juegan a lo sumo un papel secundario en el desenlace de las elecciones. O se presenta una tendencia de voto de protesta contra la política nacional a nivel local (p.ej. en Argentina), o en las elecciones en las ciudades

25 Véase Olinda Bareiro / Marcelo Duarte, Paraguay: el no debate sobre la descentralización, en: Nohlen, Descentralización, págs. 225-233. 
grandes hay un ambiente sociopolítico apto para resultados electorales diferentes que a nivel nacional (p.ej. Uruguay, Paraguay, Brasil). De todas maneras, con esas elecciones a nivel local la política se toma más compleja, la ciudadanía puede disponer de más mecanismos para expresarse en relación con la clase política.

Evaluando y sintetizando los fenómenos descritos, se puede constatar que:

1. Las elecciones a nivel local normalmente no pueden más que reflejar las tendencias nacionales mediatizadas por las características del sistema político en cuestión y por aspectos coyunturales. Así, en Chile, en las elecciones a nivel local, previstas para junio de 1992, van a dominar los mismos cinco partidos que ya ahora tienen un papel preponderante a nivel nacional, a causa de su fuerte arraigo social. En Colombia el fuerte arraigo clientelístico de los dos grandes partidos tradicionales, el Partido Conservador y el Partido Liberal, se muestra también a nivel local en el reparto de las alcaldías. En las elecciones municipales de ma ' $\supset$ de 1990 los partidos tradicionales aumentaron aún más el porcentaje de los alcaldías obtenidas: de un $86 \%$ (1988) a $88 \%$ (1990).26 Dichos partidos aprovecharon seguramente la simultaneidad de las elecciones municipales con las elecciones para el Congreso Nacional. Por el otro lado, en Uruguay el proceso de cambio político de un sistema bipartidista a un sistema de tres o cuatro partidos, que ya había empezado antes de la dictadura militar y que fue reforzado después, fue la base del triunfo del Frente Amplio en las elecciones para la intendencia de Montevideo. Y en Perú el proceso de deslegitimación de los partidos tradicionales y el auge de "outsiders" y "newcomers", signo de las elecciones presidenciales del abril/junio 1990, ya se había mostrado en cierto sentido en las elecciones municipales de noviembre de 1989, cuando en Lima ganara el candidato independiente Belmont. Hay que subrayar que sopresas locales, como el caso de las elecciones municipales en Asunción y Montevideo, se dieron en contextos con poco contenido localista o regionalista.

2. Además, en algunos países de América Latina, como p.ej. en Argentina y Brasil, las elecciones municipales fueron instrumentalizadas, como ya fue mencionado, como un voto de protesta o castigo contra la política del gobiemo central, relegando el factor local a un segundo plano.

3. Los resultados ce una democratización a nivel local van a variar entre los diferentes países de América Latina, según la modernidad de las estructuras sociales y políticas de las diferentes municipalidades: en un extremo las elecciones pueden o reforzar nuevamente el peso de elites tradicionales o crear el ámbito para que emerjan y avancen nuevas agrupaciones políticas. 
4. Las elecciones locales permiten percibir con más nitidez el respaldo dispar de los partidos políticos en diferentes ambientes sociales (rural/urbano, ciudades grandes/ciudades pequeñas, etc.). De esa manera las elecciones en las municipalidades con una estructura social más "moderna" pueden exponer tendencias futuras. En ese sentido esas elecciones funcionan como un sismógrafo para desarollos futuros, todavía imperceptibles a nivel nacional. Además, por la vía de la elección de los gobiernos locales, nuevos movimientos pueden entrar más facilmente en la arena política. Visto desde esta perspectiva, hay que constatar que en el escenario político a nivel local - especialmente en las grandes ciudades se pueden observar los contornos de la política futura a nivel nacional, las fuerzas políticas que están en auge y ' as fuerzas políticas que están en peligro de perder peso.

5. Las esperanzas de un aumento de la participación política a nivel local, como resultado de cambios en los mecanismos de elección de las autoridades locales, en general no se realizaron. También la introducción de mecanismos de participación política a nivel subcomunal normalmente despertó sólo un interés muy limitado entre los habitantes de los barrios y zonas comunales. Las experiencias de la participación a nivel sublocal no señalan - con pocas excepciones - resultados alentadores, ni en su cobertura espacial, ni en su continuidad en el tiempo.

6. Para analizar las repercusiones de procesos de descentralización en América Latina a nivel local, no es suficiente restringirse a las estructuras político-administrativas. Se debe incluir un análisis de las organizaciones intermedias, especialmente de los partidos políticos. Puede existir el caso - eso es una crítica muchas veces expresada respecto a Venezuela27 - en donde procesos descentralizadores a nivel político-administrativo chocan contra la concentración de poder en las cúpulas de los partidos políticos a nivel nacional . Hay que ver, y también existen signos en esta dirección, si las elecciones a nivel local determinan un reforzamiento de las estructuras partidarias a esos niveles. Es necesario estudiar muy cuidadosamente que repercusiones tienen los procesos de descentralización en los partidos polítici s: si ganan nuevamente peso caciques locales o si se logra una dispersión del poder en partidos demasiados centralizados. Desde un enfoque democratizador un proceso de descentralización de estructuras político-administrativas debe ser complementado con procesos semejantes en las organizaciones intermedias, aumentando su democracia interna. De tal manera "la descentralización", como escribe Bor ja28, "puede facilitar enormemente la capilaridad social de partidos políticos y organizaciones sindicales y profesionales, y por lo tanto, contribuir a su renovación y a su arraigo en la sociedad." Otros mecanismos de participación - al lado de las elecciones de las autoridades locales pueden servir como estímulo externo para reforzar ese empuje democratizador en las

27 Véase Allan R. Brewer Carías, Problemas de estado de paridos, Caracas 1988.

28 Borja, Descentralizacíon, pág. 73. 
organizaciones intermedias. En ese sentido elecciones y otros mecanismos participativos no son excluyentes, sino mutuamente reforzantes.

7. Una desconexión temporal de las elecciones a nivel nacional y local es una condición necesaria pero no suficiente para dar más peso al factor local en esas elecciones. Por esa razón se discute p.ej. una separación de las elecciones presidenciales y parlamentarias de las eleccciones para las intendencias en los departamentos en Uruguay. Al otro lado, en tiempos de recursos públicos restringidos no se puede rechazar totalmente el argumento de ahorrar costos combinando elecciones a diferentes niveles. La experiencia muestra, no solamente en América Latina, que en combinación con elecciones nacionales la tasa de participación en las elecciones municipales suele aumentar.

En conclusión: Las esperanzas de una mayor participación política a nivel local y de una renovación de la democracia en el ámbito local no se concretizaron. Pero hay signos de cambio. Actualmente nos encontramos confrontados con dos procesos paralelos que en cierto sentido se refuerzan mutuamente. Por un lado, existe un proceso de descentralización política, que está confrontado con muchos obstáculos,pero todavía abierto respecto a su desenlace. Ese proceso incluye la creación de mecanismos para una participación más amplia de la ciudadanía a nivel local (y regional). Por otro lado encontramos una volatilidad más grande del electorado - aprovechándose también de los nuevos mecanismos de participación - lo que es por un lado producto de un desgaste de los partidos tradicionales y por otro lado resultado de procesos de modemización en las sociedades respectivas, especialmente en el ambiente de las grandes ciudades. 29

Como pronóstico se puede decir que en combinación con los cambios políticos, económicos e ideológicos que caracterizaron el desarrollo de América Latina en los últimos años, la política local va a aumentar la complejidad y la dinámica de los procesos políticos en los países del continente. Estamos confrontados con una mezcla sumamente interesante: gobiernos locales (y regionales) con más competencias y más legitimidad democrática y un electorado más rebelde - o para dar votos de rechazo o para respaldar nuevas alternativas políticas. Al mismo tiempo, hay muchos municipios con ingresos insuficientes para cumplir con sus tareas y gobiernos centrales con pocas reservas financieras para compartirlas. De esa combinación de factores puede resultar una dinámica política interesante que puede conducir a un sistema político más participativo o a una grave crisis de la legitimidad del mismo.

29 Véase Robert H. Dix, Incumbency and Electoral Turnover in Latin America, en: Joumal of Interamerican Studies and World Affairs, vol. 26 (1984), págs. 435-448; Ronald H. McDonald / J. Mark Ruhl, Party Politics and Elections in Latin America, Boulder/ San Francisco / London 1989, págs. 337/348. 


\section{ABSTRACTS}

\section{Women and the Constitution in Kenya}

\section{By Kivutha Kibwana}

This paper focuses on constitutional issues vis a vis the gender question in the Kenyan context. It discusses the Constitution and sex discrimination; women's voting and representation; marriage and citizenship; implications of the co-existence of multiple systems of family law; women and property; women and human rights and finally women and legal awareness. It explores the extent to which, if at all, law and/or legal lacunae in the constitutional sphere perpetuate(s) the types of inequality that are identified and the possibility and role of activist legal engineering in ameliorating the inequalities.

The Kenyan Constitution does not bar discrimination on account of sex. Although the Constitution and other laws grant women substantial rights, including human rights, women do not adequately en joy them due to male sector negation of these, state sector condoning of continued existence of ineffectual law and a dominant culture of patriarchy and male hegemony.

\section{Local Government and Political Participation in Latin America: Processes of Decen- tralization and Electoral Change}

\section{By Detlef Nolte}

There are principally two reasons for a growing journalistic and scientific interest on the subject of "local government and political participation": (1) profound processes of political decentralization have taken place in the mayority of the Latin American countries, which resulted in a revaluation of local politics; (2) recently in some countries of the region there have been some very surprising results of municipal elections, where the dominant parties (in the national gc rernment) lost and the left and political outsiders scored important victories. The article describes both processes, analyzes their interrelation and discusses the perspectives for a profundization of democracy in Latin America. 